\title{
Apakah sistem kekerabatan matrilinieal di suku Minang masih membudaya? Analisis tematik pada makna pemberian dukungan sosial mamak kepada kemenakan
}

\author{
Niken Hartati1,2 \& Kwartarini Wahyu Yuniarti² \\ ${ }^{1}$ Fakultas Psikologi, Universitas Negeri Padang, Padang, Sumatra Barat \\ ${ }^{2}$ Fakultas Psikologi, Universitas Gadjah Mada, Yogyakarta
}

\begin{abstract}
Abstrak
Suku Minang memiliki sistem kekerabatan matrilineal di mana kesejahteraan seorang anak menjadi tanggung jawab bersama keluarga besar ibu (communal) yang dipimpin oleh mamak (saudara laki-laki ibu). Akan tetapi, penelitian-penelitian dalam bidang sosiologi memberikan bukti bahwa sistem kekerabatan tersebut sudah memudar dan peran mamak sudah digantikan oleh bapak seiring dengan menguatnya praktik keluarga inti (nuclear family). Penelitian ini berusaha mengeksplorasi tema-tema dalam makna pemberian dukungan dari perspektif mamak kepada kemenakan. Penelitian ini melibatkan 298 laki-laki Minang yang memiliki kemenakan (anak dari saudara perempuannya) dan berdomisili di provinsi Sumatra Barat yang secara tradisional mempraktikan sistem kekerabatan matrilineal. Data dikumpulkan menggunakan open-ended questionaire, dan dianalisis menggunakan pendekatan kualitatif analisis tematik. Hasil penelitian menunjukkan bahwa perilaku pemberian dukungan sosial dari mamak kepada kemenakan masih dilakukan pada mayoritas partisipan. Namun, pemberian dukungan tersebut hanya bersifat insidental dan tidak berlangsung terusmenerus. Pemberian dukungan kepada kemenakan ternyata memberikan manfaat bagi kesejahteraan afektif mamak apabila perilaku tersebut dilakukan secara tulus (altruist) dan praktik tersebut ternyata memberikan luaran sosial yang positif (rewards) seperti harga diri (self-esteem) dan perasaan terhubung (feeling social connection). Temuan lain yang menarik adalah munculnya kategori kewajiban (obligation) yang ternyata juga dapat meningkatkan kesejahteraan afektif alih-alih menjadi beban bagi mamak.
\end{abstract}

Kata kunci: dukungan sosial, mamak-kemenakan, kekerabatan matrilineal, Minangkabau

\begin{abstract}
Minangkabau people have a matrilineal kinship system in which the children's wellbeing becomes a responsibility of extended maternal family led by "Mamak" (the mother's side of uncle). How ever, mounting evidence from sociology shows that the kinship system has faded, and the role of "Mamak" has been replaced by the biological father along with the strengthening of the nuclear family. In order to explore whether such a kinship system has truly faded, we conducted a qualitative research which aimed to investigate the themes of meaningful social support that were reflectively construed by "Mamak" in their relationship with "Kemenakan". This study involved 298 Minangkabau men who possessed at least one nephew or niece (children of his sisters) at the time of the study and live in the traditionally matrilineal provinces of West Sumatra. Data was collected using the open-ended questionnaire and analyzed using a qualitative thematic analysis approach. We found that the behavior of giving support from "Mamak" to "Kemenakan" is still carried out by the majority of our respondents. However, such support is practiced as incidental, rather than continual. Providing support to nephews and nieces turned out to be beneficial for mamak's affective well-being if the behavior is done sincerely (altruist) and such practice provided positive social outcomes (rewards) such as self-esteem and the feeling of belongingness (sense of social connection). Thus, the practice of Mamak in Minangkabau culture was still seen as beneficial. However, the practice was not continual-unlike the historical tradition.
\end{abstract}

Keywords: social support, matrilineal kinship, mamak-kemenakan, Minangkabau 


\section{Pendahuluan}

Dukungan sosial merupakan salah satu bagian dari kebutuhan fundamental manusia, yaitu kebutuhan untuk terhubung (Baumeister \& Leary, 1995). Pertama, kehadiran dukungan sosial menunjukkan bahwa individu tidak terasing dari orang lain (Buchwald, 2017; House, Umberson, \& Landis, 1988). Kedua, dukungan sosial dapat meringankan masalah atau tekanan yang dialami individu (Thoits, 1986). Penelitian-penelitian terdahulu telah menemukan manfaat dukungan sosial terhadap kesehatan fisik dan psikologis (Gariepy, Honkaniemi, \& Quesnel-Vallee, 2016; Uchino, 2009; Uchino, Carlisle, Birmingham, \& Vaughn, 2011; Yasin \& Dzulkifli, 2010) bagi penerima dukungan (recipient). Selain bermanfaat bagi penerima, hasil-hasil penelitian menunjukkan bahwa penyedia dukungan (provider) ternyata juga mendapatkan keuntungan atas perilakunya. Diketahui bahwa seseorang yang memberikan dukungan bagi orang lain, cenderung lebih bahagia (Aknin, Dunn, Whillans, Grant, \& Norton, 2013; Dunn, Aknin, \& Norton, 2008; Nelson, Layous, Cole, \& Lyubomirsky, 2016; Telzer \& Fuligni, 2009), memiliki kesehatan yang lebih baik (Vaananen, Buunk, Kivimaki, Pentti, \& Vahtera, 2005), dan berusia lebih panjang (Brown, Nesse, \& Vinokur, 2003; Poulin, Brown, Dillard, \& Smith, 2013). Padahal posisi provider dalam dukungan sosial merupakan pihak yang harus mengeluarkan biaya.

Sampai dengan saat ini, riset-riset masih berusaha mengungkap mekanisme dibalik kegiatan pemberian dukungan (giving support) dengan kesehatan maupun kesejahteraan (well-being) provider (Aknin, dkk., 2013; Batson, Shaw, Batson, \& Shaw, 2009; Konrath \& Brown, 2011; Morelli, Lee, Arnn, \& Zaki, 2015; Nelson, dkk., 2016; Poulin, dkk., 2013). Akan tetapi, konteks sosial dan budaya bisa menciptakan pola berbeda dalam menerapkan dukungan sosial. Banyak riset-riset psikologi fokus pada budaya patrilineal, sementara masih jarang yang menginvestigasi budaya matrilineal (khususnya langsung di masyarakat ulayat). Riset ini berusaha mengeksplorasi makna pemberian dukungan sosial pada masyarakat dengan sistem kekerabatan matrilineal, yaitu masyarakat Minang di Sumatra Barat.

\section{Dukungan sosial}

Salah satu perspektif teori yang banyak digunakan untuk menjelaskan mekanisme tersebut adalah teori kelekatan (Attachment Theory). Teori Kelekatan (Ainsworth, 1989) meyakini bahwa pemberian dukungan bagi orang lain berakar dari dorongan alami manusia untuk merawat dan melindungi anak keturunannya yang masih rentan dan membutuhkan dukungan sampai kelak anak tersebut mandiri. Dorongan tersebut kemudian meluas pada kecenderungan individu untuk mendukung orang lain yang membutuhkan. Teori ini telah mendapatkan dukungan empirik dari riset-riset neuropsikologis yang membuktikan bahwa perilaku pemberian dukungan terprogram pada bagian otak manusia yang mengatur "parental section" yaitu dorongan untuk melindungi orang lain (Eisenberger, 2013; Inagaki \& Eisenberger, 2012; Inagaki \& Ross, 2018). Karena dipandang sebagai dorongan, maka melakukannya dapat menimbulkan kepuasan (rewarding) (Inagaki \& Orehek, 2017). Mendukung orang lain dapat meningkatkan perasaan positif pada diri individu seperti: harga diri (self esteem), keberartian diri (self worth), merasa memiliki ikatan (sense of belonging), dan kebahagiaan (happiness). Selain itu, memberikan dukungan bagi orang lain juga dapat mencegah kecenderungan untuk menarik diri (withdraw) saat seseorang mengalami tekanan, sebab mendukung orang lain ternyata dapat mengurangi persepsinya pada ancaman dan lebih mampu menghadapi tekanan (Inagaki \& Eisenberger, 2016; Inagaki \& Ross, 2018; Poulin, dkk., 2013).

Meskipun demikian, agar perilaku pemberian dukungan benar-benar dapat meningkatkan kesejahteraan pelakunya, terdapat dua persyaratan yang harus dipenuhi yaitu otonomi dan efektivitas (Inagaki \& Orehek, 2017). Otonomi mengacu pada derajat kebebasan provider dalam memutuskan untuk memberi atau tidak memberikan dukungan bagi orang lain. Seseorang yang memberikan dukungan karena keinginannya sendiri akan memiliki perasaan yang lebih positif dan harga diri yang lebih tinggi. Sebaliknya, provider berisiko tidak mendapatkan keuntungan apapun jika perilakunya merupakan hasil paksaan dari lingkungan atau berupa kewajiban karena ia kehilangan kebebasan untuk membuat pilihan (Weinstein \& Ryan, 2010). Efektivitas dukungan sosial mengacu pada persepsi provider bahwa dukungan yang diberikan mendapatkan apresiasi dari penerima sehingga terjalin ikatan sosial yang diharapkan (Orehek \& Forest, 2016). Hal ini menunjukkan bahwa tujuan utama pemberian dukungan terhadap orang lain adalah membangun ikatan sosial (Telzer \& Fuligni, 2009). Pandangan ini selaras dengan Teori Need to Belong yang merupakan turunan dari teori kelekatan. Teori ini memprediksi pemberian dukungan disebabkan oleh keinginan alamiah manusia untuk menjalin ikatan dengan orang lain. Biaya yang dikeluarkan seseorang untuk memberikan dukungan bagi orang lain lebih kecil dibandingkan kerugian akibat tidak memiliki ikatan sosial (Baumeister, 2012; Baumeister \& Leary, 1995) sehingga pemberian dukungan 
sosial merupakan bentuk dari perilaku selfpresentational yaitu perilaku yang ditujukan untuk mengesankan orang lain agar bersedia memelihara ikatan sosial dengannya.

Selain menghasilkan rewards berupa ikatan sosial, efektivitas dukungan sosial juga dapat dilihat dari dampak dukungan bagi penerima. Jika penerima mengalami perubahan yang positif setelah mendapatkan dukungan, kesejahteraan provider juga meningkat (Aknin, dkk., 2013). Tujuan pemberian dukungan sosial yang sukarela semata-mata demi kebaikan penerima alih-alih mengharapkan keuntungan bagi diri sendiri, menunjukkan berlakunya Teori Relasi Komunal dalam pemberian dukungan (Clark \& Mills, 2012; Crocker \& Canevello, 2008). Ketiga teori tersebut sama-sama memandang perilaku pemberian dukungan bermanfaat bagi pemberi jika dilakukan dengan tulus (altruist) sematamata demi kebaikan penerima dukungan dan terjalinnya ikatan sosial.

Mempertimbangkan hal tersebut, maka konteks relasi antara provider dan penerima tidak dapat diabaikan sebab kedekatan atau ikatan sosial (social bonding) antara keduanya dapat memengaruhi perilaku tersebut (Brown \& Brown, 2006; Maner \& Gailliot, 2007). Teori Kelekatan, Need to Belong, maupun Relasi Komunal sangat tepat digunakan untuk menjelaskan perilaku pemberian dukungan dalam konteks relasi dekat yang bersifat intergenerasional di mana posisi pemberi dan penerima dukungan tidak setara (asymetri) seperti relasi antara orang tua dan anak. Namun, relasi orang tua-anak bukan hanya ditentukan secara biologis atau psikis melainkan juga merupakan hasil konstruksi sosial, utamanya terkait orang tua nonmaternal (bukan ibu). Konstruksi sosial terkait relasi orang tua-anak yang unik terdapat pada sistem kekerabatan matrilineal. Alih-alih melibatkan bapak kandung sebagai orang tua yang bertanggung jawab memberikan dukungan bagi kesejahteraan anak, sistem kekerabatan matrilineal justru menempatkan saudara laki-laki ibu sebagai "bapak sosiologis" (Maria-Barbara \& Franke, 1993) yang menjadi sumber utama dukungan sosial bagi anak.

\section{Sistem kekerabatan matrilineal di suku Minang}

Munculnya sistem kekerabatan tertentu dipengaruhi oleh adaptasi masyarakat terhadap lingkungan ekologi dan keputusan investasi yang terbaik (BenYishay, Grosjean, \& Vecci, 2017). Sistem matrilineal biasanya diterapkan pada masyarakat agraris yang sumber ekonomi utamanya adalah pertanian holtikultura yang dapat dikerjakan oleh tenaga kerja perempuan dan tidak terlalu mengandalkan tenaga laki-laki.
Kondisi tersebut membuat perempuan menjadi penguasa sumber ekonomi dan karenanya lebih menguntungkan untuk berinvestasi kepada keturunan perempuan dibandingkan laki-laki (Starkweather \& Keith, 2019). Menggunakan perspektif teori "Kin Selection", para antropolog menduga bahwa sistem kekerabatan matrilineal biasanya diterapkan pada masyarakat yang memiliki "paternity confidence" yang rendah, di mana seorang laki-laki tidak dapat memastikan apakah anak yang dilahirkan istrinya merupakan anak biologisnya atau bukan (Hartung, 1985). Pada kondisi tersebut, berinvestasi pada anak saudari perempuan dipandang lebih menguntungkan daripada berinvestasi pada anak yang belum tentu keturunannya. Namun Rogers (2012) berpendapat bahwa pemberian dukungan dari lakilaki kepada kemenakan lebih disebabkan oleh kuatnya ikatan antara dirinya dengan saudari perempuannya (sibling). Kuatnya ikatan antar saudara kandung dan lemahnya ikatan antara suami dengan istri merupakan dasar terbentuknya struktur keluarga pada sistem kekerabatan matrilineal (Knight, 2008; Takyi \& Gyimah, 2007) yang membuat laki-laki secara sukarela memberikan dukungan bagi kemenakan.

Salah satu suku di Indonesia yang dikenal menerapkan budaya matrilineal adalah suku Minangkabau yang terletak di Sumatra Barat. Namun sejak tahun 1970-an, seorang antropolog telah mengungkap adanya pergeseran sosial $\mathrm{di}$ Minangkabau yang membuat peran mamak sebagai sumber dukungan sosial diambil alih oleh bapak kandung kemenakan (Kato, 1978; Schrijvers \& Postel-Coster, 1977). Perubahan sistem kekerabatan matrilineal menuju sistem kekerabatan non-matrilineal, sebenarnya juga terjadi pada suku-suku matrilineal lain di dunia, bahkan diramalkan bahwa sistem kekerabatan ini tidak lagi digunakan di masa yang akan datang (Shenk, Begley, Nolin, \& Swiatek, 2019). Penyebabnya adalah perubahan sosial seperti: pengenalan kapitalisme pada saat penjajahan Belanda yang memunculkan "man's power" yang menandingi penguasaan ekonomi oleh perempuan dan masuknya agama Islam yang memperkenalkan nilainilai patrilineal (Abraham, 2017; Blanchy, 2019; Osella, 2012; Quisumbing \& Otsuka, 2001). Ketika laki-laki Minangkabau pada akhirnya menguasai sumber ekonomi dan mengambil alih istri dan anak kandung di bawah kekuasaannya, maka ikatan antara suami-istri dalam struktur keluarga batih akan menguat bersamaan dengan melemahnya ikatan laki-laki tersebut dengan saudara perempuannya. Pada saat itu, pemberian dukungan sosial dari mamak kepada kemenakan tidak lagi menjadi prioritas, terlebih saat "paternity confidence" pada masyarakat Minangkabau turut meningkat. 
Bagi laki-laki Minangkabau, memiliki dua norma yang memuat tanggung jawab berbeda menimbulkan konsekuensi tersendiri. Natin (2008) mengatakan bahwa laki-laki Minang mengalami pertentangan batin, karena di satu sisi ia memiliki kewajiban membina dan mengawasi kemenakannya sesuai tuntutan adat, di sisi lain ia ingin menguasai anak-anaknya sesuai dorongan instingtif, yang bertentangan dengan adat. Artinya, meskipun pada penerapannya mamak lebih mengutamakan anak sendiri, tetapi terdapat konsep peran ideal yang ditanamkan budaya sehingga timbul perasaan tidak nyaman ketika seorang laki-laki tidak dapat memenuhi harapan sosial atas perannya (Blackwood, 1999). Situasi ini dikenal dengan istilah "matrilineal puzzle", yaitu situasi di mana seorang laki-laki memiliki dua tanggung jawab pada rumah asalnya (rumah ibu, saudari perempuan dan kemenakannya) dan rumah istrinya (rumahnya bersama istri dan anak-anak kandungnya). Matrilineal puzzle dapat memicu konflik dalam diri laki-laki ketika sumber daya yang dimilikinya terbatas, sehingga ia harus menetapkan prioritas antara memenuhi kebutuhan anak kandung atau kemenakannya (Shenk, dkk., 2019; Starkweather \& Keith, 2019).

Pada situasi di mana isu-isu pergeseran sosial terjadi di Minangkabau, perilaku pemberian dukungan sosial dari mamak kepada kemenakan menjadi hal yang menarik untuk diidentifikasi. Penelitian ini bertujuan mengungkap ekspresi pemberian dukungan mamak kepada kemenakan di tengah isu pergeseran sosial yang ada saat ini. Pertanyaan yang diajukan adalah apakah mamak masih memberikan dukungan bagi kemenakan? Bagaimana mamak memaknai perilaku pemberian dukungan tersebut? Temuan dalam penelitian ini juga digunakan untuk melihat apakah teori Kelekatan, Need to Belong, dan Relasi Komunal dapat menjelaskan perilaku pemberian dukungan pada relasi dekat yang bersifat intergenerasional antara mamak dan kemenakan.

\section{Metode Penelitian}

\section{Partisipan}

Partisipan yang dilibatkan dalam penelitian ini berjumlah 298 orang. Kriteria partisipan yang dipilih adalah: laki-laki dewasa yang memiliki kemenakan (anak dari saudara perempuannya) dan sudah bekerja. Kriteria sudah bekerja ditujukan untuk mengantisipasi keterbatasan sumber daya (resources) yang mungkin dibutuhkan untuk melakukan dukungan sosial. Agar hasil penelitian dapat merepresentasikan masyarakat matrilineal di Sumatra Barat, peneliti menugaskan enumerator pada beberapa wilayah mewakili wilayah darek (wilayah yang diyakini sebagai pusat peradaban matrilineal, yaitu selingkar Gunung Merapi di Sumatra Barat) seperti kota Payakumbuh dan kabupaten Limapuluh Koto $(\mathrm{n}=53)$, kota Bukittinggi dan kabupaten Agam $(\mathrm{n}=34)$, Kota Batusangkar dan Kabupaten Tanah Datar $(n=42)$, serta Padang Panjang $(n=30)$. Selain wilayah darek, peneliti juga menggali data di wilayah rantau (wilayah migrasi masyarakat Minangkabau) seperti kabupaten Pariaman $(\mathrm{n}=17)$, Kota Padang $(\mathrm{n}=110)$, dan Kabupaten Pesisir Selatan $(n=12)$. Enumerator mengunjungi partisipan yang memenuhi kriteria sesuai dengan wilayah penugasannya secara door to door. Hanya partisipan yang bersedia diwawancarai saja yang dilibatkan dalam penelitian.

\section{Desain}

Penelitian ini menggunakan desain kualitatif yang dilakukan dengan survei menggunakan open ended questionnaire yaitu kuesioner dengan pertanyaan terbuka yang dapat menjaring respon variatif dari partisipan (Creswell, 2018). Desain penelitian ini sesuai dengan tujuan penelitian yaitu mengeksplorasi perilaku pemberian dukungan sosial berdasarkan perspektif pelaku.

\section{Prosedur}

Penelitian diawali perancangan kuesioner yang ditujukan untuk mengungkap muncul atau tidaknya perilaku pemberian dukungan dan bagaimana partisipan memaknai perilakunya. Pertanyaan yang disusun sebagai berikut:

"Apakah saudara memberikan bantuan
bagi kemenakan (anak dari saudara
perempuan)?"

"Jika ya, Apakah sifat bantuan tersebut rutin atau insidental?"

“Jika tidak, jelaskan alasannya."

"Perasaan apa yang muncul setelah saudara membantu kemenakan?"

"Mengapa saudara merasakan hal
tersebut?"

Selanjutnya peneliti merekrut dua puluh enumerator yang bertugas membacakan pertanyaan, memberikan penjelasan kepada partisipan jika dibutuhkan, dan mencatat jawaban partisipan. Enumerator yang dilibatkan adalah mahasiswa Psikologi yang sudah mengikuti mata kuliah observasi dan wawancara. Sebelum ke lapangan, para enumerator mendapat pelatihan dan melakukan simulasi pada satu orang partisipan 
sekaligus melakukan uji keterbacaan. Beberapa kalimat yang tidak dipahami oleh partisipan diubah agar bisa lebih dipahami. Selanjutnya, enumerator mengambil data sesuai dengan wilayah yang ditugaskan untuknya. Setelah data terkumpul, peneliti melakukan analisis tematik, dan melakukan pemeriksaan kredibilitas penelitian dengan melibatkan tiga orang rater dalam pengambilan keputusan hasil penelitian. Dua orang rater memiliki tingkat pendidikan S2 dan satu lagi S3 dalam bidang ilmu psikologi.

\section{Teknik Analisis}

Analisis data untuk penelitian ini dilakukan dengan menggunakan analisis tematik (thematic analysis). Analisis tematik memiliki batasan yang kabur dengan beberapa metode analisis lain seperti analisis isi (content analysis), fenomenologi, dan etnografi (Javadi \& Zarea, 2016). Pendekatan ini ditujukan untuk mencari esensi dari makna dan konsep yang ada di data sehingga menghasilkan tema-tema yang ringkas. Proses analisis data diawali dengan melakukan pengorganisasian data dengan mengelompokkan jawaban partisipan berdasarkan pertanyaan. Selanjutnya, setiap jawaban akan diberi nomor kode yang menunjukkan identitas partisipannya. Persiapan data dilakukan menggunakan excel. Setelah data siap, peneliti menuju langkah selanjutnya yaitu analisis.

Langkah-langkah yang dilakukan dalam analisis data adalah: 1) melakukan pengelompokan respon partisipan sesuai dengan kemiripan kata; 2) menetapkan kata kunci untuk masingmasing kelompok; 3) mengelompokkan kembali kata-kata kunci yang memiliki kedekatan makna; 4) menetapkan nama untuk kelompok kata kunci yang memiliki kesamaan makna; dan 5) melakukan verifikasi kesesuaian antara nama kategori dengan jawaban partisipan. Proses tersebut dilakukan sampai beberapa kali (bolak-balik) dengan bantuan software MAXQDA12, sampai mendapatkan koherensi. Selanjutnya, hasil kategorisasi tersebut diserahkan kepada tiga orang rater yang mendiskusikan kesesuaian kategori dan membuat keputusan sehingga menghasilkan kategorisasi yang terverifikasi.

\section{Hasil Penelitian}

\section{Perilaku pemberian dukungan sosial}

Dilihat dari Tabel 1, dapat dikatakan hampir seluruh partisipan $(75,2 \%)$ menyatakan perannya dalam memberikan dukungan bagi kemenakan, atau setidaknya mereka pernah melakukannya di masa lalu, meskipun sekarang tidak lagi $(20,8 \%)$. Hanya sebagian kecil (4\%) yang menyatakan tidak pernah memberikan dukungan sosial dalam bentuk apapun bagi kemenakannya. Di antara partisipan yang menyatakan memberikan dukungan $(\mathrm{n}=224)$, hanya sebagian kecil $(n=39)$ yang mengaku memberikan dukungan secara rutin kepada kemenakan, setidaknya sebulan sekali. Partisipan lain $(n=185)$ hanya memberikan bantuan yang bersifat insidental, yaitu muncul sewaktu-waktu. Hal ini menunjukkan bahwa peran mamak sebagai sumber dukungan utama bagi kemenakan pada masyarakat Minangkabau memang telah bergeser, meskipun tidak menghilang.

Pemberian dukungan yang bersifat insidental umumnya $(37,9 \%)$ dilakukan ketika $m a-$ mak mempersepsi adanya kebutuhan kemenakan seperti: kemenakan membutuhkan bantuan, terjerat masalah, atau ketika ada kegiatan tertentu (lebaran, pernikahan dan kematian).

"Pada saat dibutuhkan saja, ketika kamanakan mengalami kekurangan seperti terkendala biaya sekolah." (S16)

"Apabila dibutuhkan saja yaitu apabila kamanakan terlibat perselisihan (dan) mengurusi urusan pernikahan kamanakan." (S27)

"Pada saat tertentu yaitu ketika kamanakan akan menikah, ketika membutuhkan masukan atau pandangan seorang mamak dalam membuka usaha." (S21).

Momen pemberian dukungan sosial juga terjadi ketika partisipan melakukan kontak sosial atau bertemu secara langsung dengan kemenakan $(21,1 \%)$, baik saat partisipan mengunjungi kemenakan atau kemenakan datang mengunjungi mamak, atau sekedar bertemu.

\section{"Memberikan uang saku ketika berkunjung ke rumah kemenakan" (P4) "Jika ada datang ke rumah akan diberi"
(P56)}

"Setiap kemenakan bertemu dengan saya atau datang ke rumah" (P63) 
Tabel 1

Perilaku Pemberian Dukungan Sosial

\begin{tabular}{|c|c|c|}
\hline Perilaku & $\mathrm{n}$ & $(\%)$ \\
\hline Masih Memberikan & 224 & 75,2 \\
\hline Rutin & 39 & 13,1 \\
\hline Insidental & 185 & 62,1 \\
\hline Persepsi atas kebutuhan & 113 & 37,9 \\
\hline Kontak sosial & 63 & 21,1 \\
\hline Ketersediaan sumber daya & 9 & 3,0 \\
\hline Pernah tetapi sudah tidak lagi & 62 & 20,8 \\
\hline Tidak terdapat persepsi atas kebutuhan & 43 & 14,42 \\
\hline Keterbatasan sumber daya & 11 & 3,7 \\
\hline Masalah kontak sosial & 9 & 3,0 \\
\hline Tidak pernah & 12 & 4,0 \\
\hline Keterbatasan sumber daya & 5 & 1,7 \\
\hline Masalah kontak sosial & 4 & 1,3 \\
\hline Tidak terdapat persepsi atas kebutuhan & 3 & 1,0 \\
\hline
\end{tabular}

Sebagian kecil partisipan (3\%) memberikan dukungan ketika merasa memiliki sumber daya yang lebih, seperti pernyataan:

"Ketika mempunyai rezeki berlebih setelah gajian" (P14)

"Karena tergantung dari mamaknya jika mamaknya ada rezeki maka ia akan membantu kamenakannya" (P202).

Mamak yang menyatakan pernah memberikan dukungan kepada kemenakan di masa lalu ( $n=62)$ menyebutkan beberapa alasan penghentian dukungan. Alasan pertama ialah si kemenakan dipersepsi tidak memiliki kebutuhan lagi $(14,42 \%)$ karena mereka sudah mandiri atau karena orang tua si kemenakan dapat memenuhi sendiri kebutuhan anaknya.

"Karena mereka telah berhasil dan sukses semuanya, maka rasanya tidak ada yang harus dibantu lagi." (S259).

Alasan kedua adalah keterbatasan sumber daya $(3,7 \%)$, misalnya karena mamak mengalami perubahan kondisi ekonomi atau karena keluarga batih mamak lebih membutuhkan.

"Karena saat ini sedang membutuhkan banyak dana untuk sekolah dan pengobatan istri." (S108)

"Karena beban hidup sekarang dan tanggungan yang sudah lebih besar, sehingga sulit untuk memberikan dukungan dan bantuan..." (S45).
Masalah kontak sosial (3\%) menunjukkan adanya "jarak" baik fisik (karena mamak tinggal berjauhan) maupun psikologis (karena adanya relasi yang kurang harmonis).

\section{"Kalau dulu tinggalnya jauh dan sekarang sibuk mengurusi anak saya sendiri dan sibuk bekerja." (S258).}

Hampir seluruh partisipan menyatakan bahwa dirinya memberikan dukungan sosial bagi kemenakan, setidak-tidaknya pernah memberi dukungan di masa lalu. Namun, terdapat beberapa orang mamak $(\mathrm{n}=12)$ yang mengaku tidak pernah memberikan dukungan apapun kepada kemenakan. Adapun alasan pertama yang dikemukakan adalah keterbatasan sumber daya $(1,7 \%)$ seperti yang terdapat pada kutipan, "Penghasilan yang pas pasan" (S120). Alasan kedua, masalah dalam kontak sosial $(1,3 \%)$ yang menciptakan jarak psikologis, seperti pada kutipan berikut:

\section{"Harta pusaka sudah diambil oleh saudara perempuan dan tenggang rasa terhadap saudara juga sudah tidak ada lagi." (S91)}

Alasan ketiga adalah tidak terdapat persepsi atas kebutuhan kemenakan (1\%), seperti pernyataan: "Mereka sudah dewasa dan berpenghasilan sendiri." (S85).

Berdasarkan hasil tersebut, dapat disimpulkan terdapat tiga faktor yang memengaruhi muncul atau tidaknya perilaku pemberian dukungan sosial dari mamak kepada kemenakan, yakni persepsi terhadap ada atau tidaknya kebutuhan, harmonis atau tidaknya kontak sosial antara mamak dengan kemenakan dan tersedia atau tidaknya sumber daya. 


\section{Perasaan yang mengiringi perilaku pem- berian dukungan}

Dari 282 partisipan yang memberikan dukungan bagi kemenakan atau setidaknya pernah memberikan dukungan, hampir seluruhnya (94\%) merasa positif setelah perilakunya ditampilkan. Perasaan positif yang dimaksud disebutkan partisipan sebagai perasaan senang, lega, bahagia, puas, dan bangga. Sekitar empat belas partisipan (5\%) merasa netral atau biasa dan ada tiga orang partisipan yang merasa negatif $(1,1 \%)$ yaitu sedih dan belum puas setelah memberikan dukungan.

\section{Makna Pemberian Dukungan Sosial}

Makna pemberian dukungan sosial didapatkan dari alasan munculnya perasaan pada kategori di atas. Respon partisipan dikategorikan berdasarkan istilah-istilah yang ada dalam teori yang menjadi acuan dalam artikel ini yaitu Teori Kelekatan, Need to Belong, dan Relasi Komunal. Meskipun demikian, terdapat juga kategori yang muncul berdasarkan respon partisipan, yang tidak termaktub dalam teori tersebut. Terdapat tiga kategori besar makna pemberian dukungan bagi mamak yaitu "rewards," "altruist", dan "obligation." Sebaran frekuensinya dapat dilihat pada Tabel 2.

Kategori "reward" menunjukkan bahwa pemberian dukungan sosial yang dilakukan oleh mamak ternyata memberikan keuntungan bagi dirinya yaitu mendapatkan luaran sosial yang positif seperti harga diri (self-esteem), perasaan terhubung (feeling social connection), dan perasaan positif (positive affect). Harga diri (44,7\%) merupakan makna yang paling dominan yang dimunculkan oleh perasaan bermanfaat, kepatuhan kemenakan, dan pengakuan.

\section{"Supaya kemenakan tahu dengan (peran) mamak" (Mk/46) \\ "Merasa sudah dihargai dan dibutuhkan oleh kemenakan" (Mk/59).}

Memberikan dukungan juga dimaknai sebagai perasaan terhubung menunjukkan adanya keinginan untuk menjadi bagian dari relasi sosial, meskipun frekuensinya tidak terlalu tinggi (4,6\%). Kategori ini terdiri dari dua sub kategori, menimbulkan kedekatan dan resiprokal. Hal ini menunjukkan bahwa tujuan pemberian dukungan sosial adalah ikatan sosial yang memastikan posisi partisipan sebagai bagian dari kelompok (Need to Belong).

\section{"Karena bisa menjadi lebih akrab dengan kemenakan (Mk.210)"}

"Apabila saya sudah usia tua, kemenakan bisa memberikan bantuan kepada saya." (Mk/149)

Terakhir, reward juga didapat langsung dari perasaan positif yang mengiringi perilaku pemberian dukungan sosial, meskipun persentasenya sangat kecil $(2,8 \%)$.

Kategori makna pemberian dukungan sosial kedua adalah "altruist" (19,9\%), mengacu perilaku yang semata-mata ditujukan untuk kebaikan penerima. Kategori ini terdiri dari sub kategori yang dirumuskan mendekati respon partisipan yaitu kemenakan bahagia dan perubahan positif bagi kemenakan kategori ini menunjukkan bahwa perilaku pemberian dukungan dari mamak difokuskan secara tulus untuk meningkatkan kesejahteraan kemenakan seperti membuatnya bahagia dan bertumbuh secara positif seperti halnya relasi komunal. Contoh pernyataan dari kategori tersebut adalah:

\section{"Karena saya merasa senang saja melihat kemenakan saya senang dari pemberian saya." (Mk/70) \\ "Karena kamanakan bisa berubah dan mendengarkan nasihat yang disampai- kan." (Mk/34)}

Kategori ketiga yaitu “obligation," memiliki frekuensi cukup besar (28\%). Kategori ini terdiri dari sub kategori seperti: keberhasilan melaksanakan kewajiban, beban tanggung jawab, kewajiban yang belum maksimal, dan usaha melanjutkan tradisi.

"Karena telah berhasil menjalankan
peran sebagai seorang mamak."
$(\mathrm{Mk} / 28)$

"Karena saya bisa menjalankan peran saya sebagai mamak." (Mk/30) 
Tabel 2

Makna Pemberian Dukungan Sosial

\begin{tabular}{lcc}
\multicolumn{1}{c}{ Kategori Makna } & $\mathrm{n}$ & $(\%)$ \\
\hline Reward & 147 & 52,1 \\
Self-esteem & 126 & 44,7 \\
Merasa bermanfaat & 96 & 34,0 \\
Kemenakan mematuhi & 22 & 7,8 \\
Kontak sosial & 8 & 2,8 \\
Pengakuan & 13 & 4,6 \\
Feeling social connection & 8 & 2,8 \\
Menimbulkan kedekatan & 5 & 1,8 \\
Resiprokal & 8 & 2,8 \\
Positive affect & 56 & 19,9 \\
Altruist & 15 & 5,3 \\
Kemenakan bahagia & 41 & 14,5 \\
Perubahan positif bagi kemenakan & 79 & 28,0 \\
Obligation & 65 & 23,0 \\
Keberhasilan melaksanakan kewajiban & 8 & 2,8 \\
Beban tanggung jawab & 4 & 1,4 \\
Kewajiban yang belum maksimal & 2 & 0,7 \\
Melanjutkan tradisi & 147 & 52,1 \\
\hline
\end{tabular}

Tabel 3

Perasaan dan Pemaknaan Perilaku Pemberian Dukungan

\begin{tabular}{lccc} 
& Perasaan & \multicolumn{3}{c}{ Kategori Makna } \\
\cline { 2 - 4 } & Altruist & Reward & Obligation \\
\hline Positif & 54 & 147 & 64 \\
Senang & 40 & 115 & 32 \\
Lega & 4 & 8 & 17 \\
Bahagia & 4 & 8 & 5 \\
Puas & 4 & 7 & 6 \\
Bangga & 2 & 9 & 3 \\
Negatif & 0 & 0 & 2 \\
Sedih & 0 & 0 & 1 \\
Belum puas & 0 & 0 & 12 \\
Netral & 2 & 0 & \\
\hline
\end{tabular}

Kategori ini mencerminkan pemberian dukungan sosial yang diinisiasi oleh nilai-nilai dan norma sosial, bukan berasal dari dorongan alami seperti yang terdapat pada Teori Kelekatan maupun Need to Belong. Kewajiban membuat mamak kehilangan otonomi untuk mendukung atau tidak mendukung kemenakan, dapat juga dikatakan sebagai "paksaan" yang kontraproduktif dengan manfaat dukungan sosial bagi provider. Peneliti memberikan data silang antara perasaan dan makna pemberian dukungan sosial pada Tabel 3 berikut untuk mengetahui lebih lanjut bagaimana perasaan partisipan yang berkaitan dengan makna pemberian dukungan, utamanya pada kategori "obligation."

Perasaan positif mendominasi pemberian dukungan sosial yang dimaknai sebagai tindakan altruis maupun memberikan reward bagi provider, tetapi mamak yang memaknai perilaku pemberian dukungan sebagai bentuk kewajiban (obligation) memiliki perasaan yang beragam baik positif, negatif maupun netral.

\section{Diskusi}

Penelitian ini mampu memberikan gambaran representatif mengenai perilaku pemberian dukungan sosial dari mamak kepada kemenakan karena partisipan yang dilibatkan telah mewakili wilayah-wilayah di Sumatra Barat. Meskipun penelitian terdahulu menyebutkan terjadinya pergeseran peran mamak di mata kemenakan (Fahma, 2018; Hafiza, 2019; Handayani \& Pinasti, 2018; Hayati, 2019; Yusutria, 2018), tetapi temuan dalam penelitian ini memastikan bahwa peran mamak sebagai salah satu alternatif sumber dukungan bagi kemenakan belum menghilang. Secara teoritis, penelitian ini memberikan kontribusi terhadap pengembangan teori dukungan sosial, utamanya pada relasi dekat yang bersifat intergenerasional dari sisi pemberi dukungan (provider). Temuan penelitian ini juga dapat menjelaskan faktor-faktor yang mengantarai perilaku pemberian dukungan dengan kesejahteraan afektif provider. 
Penelitian ini berhasil mengungkap tiga kondisi yang mendahului perilaku pemberian dukungan yaitu: persepsi mamak terhadap kebutuhan kemenakan, kontak sosial yang harmonis dan ketersediaan sumber daya yang dibutuhkan. Persepsi terhadap kebutuhan menunjukkan bahwa dukungan yang diberikan mamak ditujukan untuk mengatasi masalah kemenakan sebagai bentuk coping assistance (Thoits, 1986). Persepsi terhadap kebutuhan juga menunjukkan adanya empathic concern dari pihak mamak yang memunculkan kerelaan untuk memberikan dukungan bagi orang lain (Maner \& Gailliot, 2007). Namun, empathic concern hanya muncul pada pemberian dukungan pada relasi dekat dengan karakteristik kontak sosial yang harmonis, sebab relasi yang kuat antara provider dengan penerima merupakan prediktor kuat bagi terjadinya transfer dukungan (Buchwald, 2017). Memberikan dukungan bagi orang yang disayangi, lebih mungkin dilakukan secara tulus dibandingkan memberikan dukungan bagi orang asing (Inagaki \& Eisenberger, 2012; Morelli dkk., 2015; Nelson, dkk., 2016). Kedua prasyarat tersebut menunjukkan kedekatan relasi antara mamak dan kemenakan yang memungkinkan terjadinya transfer dukungan yang tulus seperti yang dijelaskan dalam Teori Kelekatan, Need to Belong, maupun Relasi Komunal. Meskipun mamak memiliki keinginan untuk memberikan dukungan bagi orang yang disayangi, tetapi eksekusi perilaku tersebut dapat dibatasi oleh sumber daya yang dimiliki provider (Inagaki \& Orehek, 2017). Jika mamak memiliki sumber daya yang dibutuhkan kemenakan, maka dukungan akan diberikan.

Selain dapat mengidentifikasi prasyarat, penelitian ini juga membuktikan bahwa pemberian dukungan bermanfaat bagi kesejahteraan afektif provider yaitu mamak merasa lebih positif setelah memberikan dukungan bagi kemenakan. Perasaan positif tersebut muncul pada mereka yang memberikan dukungan secara sukarela (altruist) semata-mata demi kesejahteraan kemenakan. Hal ini menjadi lebih mudah dilakukan karena mamak dan kemenakan memiliki relasi biologis (Brown \& Brown, 2006). Pemberian dukungan juga dapat memuaskan kebutuhan akan ikatan sosial (Need to Belong) karena provider mendapatkan luaran sosial yang positif seperti harga diri dan perasaan terhubung. Selain mendapatkan luaran sosial, perilaku mendukung saja sudah secara langsung dapat memunculkan perasaan positif, yang menunjukkan bahwa perilaku ini dimunculkan oleh dorongan alami individu (insting) dan konteks relasi dekat antara mamak-kemenakan.

Paksaan atau kewajiban yang menghilangkan otonomi provider, berpotensi mengurangi manfaat pemberian dukungan bagi provider
(Inagaki \& Orehek, 2017). Beberapa mamak telah menunjukkan situasi tersebut, tetapi yang mengejutkan adalah sebagian besar mamak justru merasakan afek positif meskipun memaknai perilakunya sebagai kewajiban. Hal ini menunjukkan mekanisme yang berbeda dari yang ditawarkan teori Kelekatan maupun Need to Belong yang memiliki dasar biologis. Pendekatan lain seperti Teori Identitas Diri lebih tepat digunakan untuk menjelaskan fenomena tersebut. Ketika mamak mengidentifikasi dirinya sebagai bagian dari kelompok sosialnya, maka ia akan melaksanakan tugas dan kewajiban sesuai dengan perannya (Jetten, Haslam, Iyer, \& Haslam, 2010). Sistem kekerabatan matrilineal dengan jelas mengatur tugas mamak sebagai "bapak sosiologis" bagi kemenakan, sehingga keberhasilan dalam melaksanakannya akan menimbulkan perasaan positif. Sebaliknya, kegagalan dapat menimbulkan perasaan negatif seperti yang ditemukan dalam penelitian ini.

\section{Kesimpulan}

Meskipun relasi kekerabatan matrilineal dikatakan memudar, ternyata para mamak di Sumatra Barat masih tetap mempertahankan perannya sebagai provider dukungan sosial bagi kemenakan. Terdapat tiga kondisi yang memunculkan dukungan sosial: persepsi terhadap kebutuhan, kontak sosial yang harmonis, dan ketersediaan sumber daya. Penelitian ini juga menunjukkan bahwa mamak sebagai provider dukungan sosial juga mendapat manfaat atas perilakunya berupa kesejahteraan afektif jika mamak melakukannya atas dorongan alami yang altruis dan mendapatkan luaran sosial yang menguatkan ikatan sosial yang dimiliki. Perilaku pemberian dukungan yang dipaksakan atau dipersepsi sebagai kewajiban, berpotensi mengurangi kesejahteraan afektif mamak. Meskipun demikian persepsi terhadap kewajiban masih dapat meningkatkan kesejahteraan afektif ketika mamak mengadopsi norma dan nilai sosial dari budaya matrilineal terkait kewajiban mamak terhadap kemenakan dan melaksanakannya dengan sebaik-baiknya.

\section{Keterbatasan dan Saran}

Penelitian ini dapat mengungkap perilaku dan makna pemberian dukungan sosial mamak terhadap kemenakan di Sumatra Barat, sayang penelitian ini tidak membandingkannya dengan perilaku pemberian dukungan kepada non-kemenakan seperti anak kandung atau kerabat istri. Padahal perbandingan tersebut dapat memperjelas keunikan relasi mamak-kemenakan. Disarankan bagi peneliti selanjutnya untuk mengungkap dinamika yang dapat menjelaskan 
dinamika yang mengantarai persepsi pemberian dukungan sebagai kewajiban dengan luaran yang positif pada mamak seperti yang ditemukan dalam penelitian ini, tetapi belum mendapatkan penjelasan yang empirik.

\section{Daftar Pustaka}

Abraham, J. (2017). Setting sail for Lakshadweep : Leela Dube and the study of matrilineal kinship. Indian Journal of Gender Studies, 24(3), 438-454. https://doi.org/10.1177/0971521517716 813

Ainsworth, M. D. S. (1989). Attachments beyond infancy. American Psychologist, 44(4), 709716.

Aknin, L. B., Dunn, E. W., Whillans, A. V, Grant, A. M., \& Norton, M. I. (2013). Making a difference matters: Impact unlocks the emotional benefits of prosocial spending. Journal of Economic Behavior and Organization, 88, 90-95. https://doi.org/10.1016/j.jebo.2013.01.00 8

Batson, C. D., Shaw, L. L., Batson, C. D., \& Shaw, L. L. (2009). Evidence for altruism: Toward a pluralism of prosocial motives. Psychological Inquiry: An International Journal for the Advancement of Psychological Theory, (September 2012), 37-41.

Baumeister, R. F. (2012). Need-to-belong theory. In P. a. M. Van Lange, A. W. Kruglanski, \& E. T. Higgins (Eds.), Handbook of theories of social psychology (1st ed., p. 121). London: Sage Publications Ltd.

Baumeister, R. F., \& Leary, M. R. (1995). The need to belong: Desire for interpersonal attachments as a fundamental human motivation. Psychology Bulletin, 117(3), 497-529.

BenYishay, A., Grosjean, P., \& Vecci, J. (2017). The fish is the friend of matriliny : Reef density and matrilineal inheritance tr. Journal of Development Economics, 127(February), 234-249.

https://doi.org/10.1016/j.jdeveco.2017.0 3.005

Blackwood, E. (1999). Big houses and small houses: Doing matriliny in West Sumatra. Journal of Anthropology, 64(1), 32-56. https://doi.org/10.1080/00141844.1999. 9981589

Blanchy, S. (2019). A matrilineal and matrilocal Muslim society in flux: negotiating gender and family relations in the Comoros. Africa, 89(1), 21-39. https://doi.org/10.1017/S000197201800

\section{2}

Brown, S. L., \& Brown, R. M. (2006). Selective investment theory: Recasting the functional significance of close relationships. Psychological Inquiry, 17(1), 1-29.

Brown, S. L., Nesse, R. M., \& Vinokur, A. D. (2003). Providing social support may be more beneficial than receiving it: Results from a prospective study of mortality. Psychological Science, 14(4), 320-327.

Buchwald, P. (2017). Social support. In Reference Module in Neuroscience and Biobehavioral Psychology (pp. 1-6).

Clark, M. S., \& Mills, J. R. (2012). A Theory of communal (and exchange) relation. In P. a. M. Van Lange, A. W. Kruglanski, \& E. T. Higgins (Eds.), Handbook of theory of social psychology (1st ed., p. 232). London: Sage Publications Ltd.

Crocker, J., \& Canevello, A. (2008). Creating and undermining social support in communal relationships: The role of compassionate and self-image goals. Journal of Personality and Social Psychology, 95(3), 555-575. https://doi.org/10.1037/00223514.95.3.555

Dunn, E. W., Aknin, L. B., \& Norton, M. I. (2008). Spending money on others promotes happiness. Science, 319(March), 16871688.

Eisenberger, N. I. (2013). An empirical review of the neural underpinnings of receiving and giving social support: Implications for health. Psychosomatic Medicine, 75(6), 545556.

https://doi.org/10.1097/PSY.0b013e3182 9de2e7

Fahma. (2018). Pergeseran peran ninik mamak dalam membentuk keluarga sakinah pada masyarakat Minangkabau perspektif teori peran: Studi Kasus Malalak Timur Kabupaten Agam Sumatra Barat. Universitas Islam Negeri Maulana Malik Ibrahim.

Gariepy, G., Honkaniemi, H., \& Quesnel-Vallee, A. (2016). Social support and protection from depression: Systematic review of current findings in western countries. The British Journal of Psychiatry, 209, 284-293. https://doi.org/10.1192/bjp.bp.115.1690 94

Hafiza. (2019). Pergeseran fungsi mamak kandung dalam pelaksanaan adat Minangkabau pada masyarakat Jorong Batu Badinding Nagari Limo Koto Kecamatan Bonjol Kabupaten Pasaman. Jurnal Ilmu Budaya, 16(1).

Handayani, M., \& Pinasti, V. I. S. (2018). 
Pergeseran peran ninik mamak pada masyarakat Minangkabau dalam era modernisasi: Studi kasus di Nagari Kamang Hilia, Kecamatan Kamang Magek, Agam, Sumatra Barat. E-Societas, 7(7), 1-15.

Hartung, J. (1985). Matrilineal inheritance: New theory and analysis. The Behavioral and Brain Sciences, 8, 661-688.

Hayati, R. (2019). Kedudukan mamak dalam masyarakat adat Nagari Kamang Mudik menurut perspektif hukum Islam: Analisis terhadap pergeseran kewenangan paman sebagai hakam dalam hukum keluarga. Universitas Islam Negeri Sultan Syarif Kasim Riau.

House, J. S., Umberson, D., \& Landis, K. R. (1988). Structures and processes of social support. Annual Review Sociology, 14, 293-318.

Inagaki, T. K. (n.d.). Neural mechanisms of the link between giving social support and health. Annals of the New York Academy Sciences.

Inagaki, T. K., \& Eisenberger, N. I. (2012). Neural correlates of giving support to a loved one. Psychosomatic Medicine, 74(1), 3-7.

Inagaki, T. K., \& Eisenberger, N. I. (2016). Giving support to others reduces sympathetic nervous system-related responses to stress. Psychophysiology, 53, 427-435. https://doi.org/10.1111/psyp.12578

Inagaki, T. K., \& Orehek, E. (2017). On the benefits of giving social support: When, why, and how support providers gain by caring for others. Current Directions in Psychological Science, 26(2), 109-113. https://doi.org/10.1177/0963721416686 212

Inagaki, T. K., \& Ross, L. P. (2018). Neural correlates of giving social support: Differences between giving targeted versus untargeted support. Psychosomatic Medicine, 80(October), 724-732. https://doi.org/10.1097/PSY.0000000000 000623

Javadi, M., \& Zarea, K. (2016). Understanding thematic analysis and its pitfall. Journal of Client Care, 1(1), 34-40. https://doi.org/10.15412/J.JCC.02010107

Jetten, J., Haslam, S. A., Iyer, A., \& Haslam, C. (2010). Turning to others in times of change: Social identity and coping with stress. In S. Sturmer \& M. Snyder (Eds.), The Psychology of Prosocial Behavior (1st ed., pp. 139-156). Malden: Wiley-Blackwell.

Kato, T. (1978). Change and continuity in the Minangkabau matrilineal system. Indonesia, 25(April), 1-16.

Knight, C. (2008). Early human kinship was matrilineal. In H. Callan, R. Dunbar, \& W. James (Eds.), Early human kinship: From sex to social reproduction (1st ed., pp. 61-82). Malden: Blackwell Publising.

Konrath, S., \& Brown, S. (2011). The effects of giving on givers. In $\mathrm{N}$. Roberts \& $\mathrm{M}$. Newman (Eds.), Handbook of Health and Social Relationships (In press, pp. 1-20). APA Books.

Maner, J. O. N. K., \& Gailliot, M. T. (2007). Altruism and egoism: Prosocial motivations for helping depend on relationship context. European Journal of Social Psycology, 358(August 2006), 347-358. https://doi.org/10.1002/ejsp.364

Maria-Barbara, \& Franke, W. (1993). The Lycian heritage and the makin of men: Matrilineal models for parenting. Women's Studies International Forum, 16(6), 569-579. https://doi.org/10.1016/S02775395(08)80002-7

Morelli, S. A., Lee, I. A., Arnn, M. E., \& Zaki, J. (2015). Emotional and instrumental support provision interact to predict wellbeing. Emotion, 15(4), 484-493.

Natin, S. (2008). Perubahan sosial kedudukan dan peran mamak terhadap anak dan kemenakan di ranah minang. Mimbar Hukum, 20(2), 193-410.

Nelson, S. K., Layous, K., Cole, S. W., \& Lyubomirsky, S. (2016). Do unto others or treat yourself? The effects of prosocial and self-focused behavior on psychological flourishing. Emotion, 16(6), 850-861.

Orehek, E., \& Forest, A. L. (2016). When people serve as means to goals: Implications of a motivational account of close relationships. Current Directions in Psychological Science, 25(2), 79-84. https://doi.org/10.1177/0963721415623 536

Osella, C. (2012). Desires under reform: Contemporary reconfigurations of family , marriage, love and gendering in a transnational south Indian matrilineal muslim community. Culture and Religion, 13(2 (June)), 241-264. https://doi.org/10.1080/14755610.2012. 675508

Poulin, M. J., Brown, S. L., Dillard, A. J., \& Smith, D. M. (2013). Giving to others and the association between stress and mortality. American Journal of Public Health, 103(9), 1649-1655. https://doi.org/10.2105/AJPH.2012.3008 76

Quisumbing, A. R., \& Otsuka, K. (2001). Land inheritance and schooling in matrilineal societies: Evidence from Sumatra. World Development, 29(12), 2093-2110.

Rogers, A. R. (2012). Genetic relatedness to 
sisters ' children has been underestimated.

Proc. $R$ Soc B, 280, 20121937. https://doi.org/10.1098/rspb.2012.1937

Schrijvers, J., \& Postel-coster, E. (1977). Minangkabau women: Change in a matrilineal society. Archipelago, 13, 79103.

Shenk, M. K., Begley, R. O., Nolin, D. A., \& Swiatek, A. (2019). When does matriliny fail? The frequencies and causes of transitions to and from matriliny estimated from a de novo coding of a cross-cultural sample. Phil. Trans. R. Soc. B, 374, 20190006. https://doi.org/10.1098/rstb.2019.0006

Starkweather, K., \& Keith, M. (2019). One piece of the matrilineal puzzle : the socioecology of maternal uncle investment. Phil. Trans. $R$. Soc. B, 374(20180071), 1-12.

Takyi, B. K., \& Gyimah, S. O. (2007). Matrilineal family ties and marital dissolution in Ghana. Journal of Family Issues, 28(5), 682705.

https://doi.org/10.11770192513X062976 23

Telzer, E. H., \& Fuligni, A. J. (2009). Daily family assistance and the psychological well-being of adolescents from Latin American, Asian , and European backgrounds. Developmental Psychology, 45(4), 1177-1189. https://doi.org/10.1037/a0014728

Thoits, P. A. (1986). Social Support as Coping Assistance. Journal of Consulting and Clinical Psychology, 54(4), 416-423.

Uchino, B. N. (2009). Understanding the links between social support and physical health: A life-span perspective with emphasis on the separability of perceived and received support. Perspectives on Psychological Science, 4(3), 236-256.

Uchino, B. N., Carlisle, M., Birmingham, W., \& Vaughn, A. A. (2011). Social support and the reactivity hypothesis: Conceptual issues in examining the efficacy of received support during acute psychological stress. Biological Psychology, 86(2), 137-142. https://doi.org/10.1016/j.biopsycho.2010 .04 .003

Vaananen, A., Buunk, B. P., Kivimaki, M., Pentti, J., \& Vahtera, J. (2005). When it is better to give than to receive: Long-term health effects of perceived reciprocity in support exchange. Journal of Personality and Social Psychology, 89(2), 176-193. https://doi.org/10.1037/00223514.89.2.176

Weinstein, N., \& Ryan, R. M. (2010). When helping helps: Autonomous motivation for prosocial behavior and its influence on well-being for the helper and recipient. Journal of Personality and Social Psychology, 98(2), 222-244. https://doi.org/10.1037/a0016984

Yasin, M. A. S. M., \& Dzulkifli, M. A. (2010). The relationship between social support and psychological problems among students. International Journal of Business and Social Science, 1(3), 110-116.

Yusutria, R. F. (2018). Robohnya lembaga pendidikan surau. Jurnal Kependidikan Dan Keagamaan, 2(1). 